\title{
Modelo para a gestão da cultura de segurança do trabalho em organizações industriais
}

\author{
Anastácio Pinto Gonçalves Filho ${ }^{\mathrm{a} *}$, José Célio Silveira Andrade \\ Marcia Mara de Oliveira Marinhoc \\ a*anastaciofilho@ufba.br, SRTE, Brasil \\ bceliosa@ufba.br, UFBA, Brasil \\ 'marma@ufba.br, UFBA, Brasil
}

\section{Resumo}

A pesquisa apresentada neste artigo teve o objetivo de desenvolver e validar um modelo para identificar o estágio de maturidade da cultura de segurança do trabalho em organizações industriais. Com a finalidade de validá-lo, o modelo desenvolvido foi aplicado em 23 empresas químicas e petroquímicas do Polo Industrial de Camaçari, Bahia, Brasil. Foram utilizados os seguintes métodos para validação do modelo desenvolvido: 1) entrevistas individuais, 2) evidências documentais, 3) entrevistas com grupo de gerentes e 4) aplicação do modelo em outro ramo de atividade diferente do ramo químico e petroquímico. 0 principal resultado obtido foi que o modelo desenvolvido foi validado e pode ser utilizado para identificar o estágio de maturidade da cultura de segurança em organizações industriais.

Palavras-chave

Maturidade da cultura de segurança. Gestão da segurança do trabalho. Organizações industriais.

\section{Introdução}

Segundo dados do Ministério da Previdência e Assistência Social (MPAS), no período de 2004 a 2008, foram registrados 2.888 .798 acidentes de trabalho no país, o que correspondente a uma média de 577.760 acidentes registrados por ano, sendo desse total 14.005 com óbitos, média de 2.800 óbitos/ ano (BRASIL, 2007, 2008). Esses dados mostram que os acidentes de trabalho constituem um problema bastante grave no Brasil.

A comparação do coeficiente de mortalidade do Brasil, de 16,6 mortes por 100.000 trabalhadores, com o de outros países, tais como Finlândia de 2,9; França de 3,0; Canadá de 6,4 e Espanha de 1,9, demonstram que o risco de morrer por acidente de trabalho no Brasil é cerca de três a oito vezes maior do que naqueles paises (HAMALAINEM; TAKALA; SAARELA, 2006).

Os acidentes de trabalho acarretam elevados custos econômicos e sociais para as empresas, para a sociedade e para as famílias das vítimas. Embora seja de difícil quantificação devido sua parcela invisível, como a dor das famílias dos acidentados, a perda da vida, a incapacidade para o trabalho, Pastore (2001) estimou que os custos ocasionados por esses infortúnios atinjam cerca de 20 bilhões de reais por ano no Brasil, ocasionado pelo tempo perdido, pelas despesas com os primeiros socorros, pela destruição dos equipamentos e materiais, pela interrupção da produção, pelo retreinamento da mão de obra, pela substituição de trabalhadores, pelo pagamento de horas extras, pela recuperação de empregados, pelos salários pagos aos trabalhadores afastados, palas despesas administrativas, pelos gastos com medicina e engenharia de reparação.

Com o objetivo de compreender os fatores que se encontram subjacentes a um número tão elevado de acidentes, existe uma disposição de mudar as abordagens tradicionais dos estudos sobre segurança no trabalho, que se caracterizam por analisar problemas pontuais, tais como os relacionados com o uso 
dos equipamentos de proteção individual (EPI), implantação das medidas de proteção coletiva, treinamento, punição, educação dos trabalhadores, não cumprimento das normas de segurança e dos procedimentos. A nova tendência é a abordagem mais ampla, como, por exemplo, procurar identificar os impactos dos fatores organizacionais, como a gestão, o planejamento e a cultura, na segurança do trabalho (NEAL; GRIFFIN; HART, 2000; MEARS; WHITAKER; FLIN, 2003).

Fatores relacionados com cultura organizacional podem influenciar no sucesso e no bom desempenho do sistema de gestão da segurança do trabalho - SGST da organização, pois é num contexto onde existe cultura de segurança que as atitudes e o comportamento dos indivíduos relativo à segurança se desenvolvem $\mathrm{e}$ persistem. É por esta razão que o conceito de cultura de segurança tem recebido atenção, pois os sistemas de gestão funcionarão melhor em organizações que tenham atingido um determinado estágio de maturidade da cultura de segurança (EK et al., 2007; HOPKINS, 2005; MEARNS; WHITAKER; FLIN, 2003).

A pesquisa apresentada neste artigo teve o objetivo de desenvolver um modelo para identificar o estágio de maturidade da cultura de segurança nas organizações industriais. Com a finalidade de validá-lo, o modelo desenvolvido foi aplicado em 23 empresas químicas e petroquímicas do Polo Industrial de Camaçari, Bahia, Brasil. Foram utilizados os seguintes métodos para validação do modelo desenvolvido: 1) entrevistas individuais, 2) evidências documentais, 3) entrevistas com grupo de gerentes e 4) aplicação do modelo em outro ramo de atividade diferente do ramo químico e petroquímico.

\section{Cultura de segurança}

0 conceito de cultura de segurança surge em 1988 no primeiro relatório técnico realizado pelo International Nuclear Safety Advisory Group (INSAG), onde é apresentado o resultado da análise do acidente da usina nuclear de Chernobyl, na Ucrânia (AGÊNCIA..., 1991). Os erros e violações de procedimentos que contribuíram, em parte, para este acidente foram interpretados como sendo uma evidência da existência de uma fraca cultura de segurança em Chernobyl, em particular, e na indústria soviética, em geral. Nesse relatório, a cultura de segurança foi definida como "o conjunto de características e atitudes das organizações e dos indivíduos, que garante que a segurança de uma planta nuclear, pela sua importância, terá a maior prioridade" (INSAG, 1988, apud AGÊNCIA..., 1991, p. 1).
Desde a introdução do conceito pelo INSAG, o termo rapidamente ganhou o dicionário do gerenciamento de segurança, e o conceito foi utilizado como um substantivo tema em relatórios oficiais de desastres e grandes acidentes (FLIN et al., 2000). Nos anos de 1990, o tema cultura de segurança foi alvo de um grande desenvolvimento teórico e empírico. Nesse período, houve uma proliferação de estudos sobre cultura de segurança, com o objetivo de conceituá-la e desenvolver instrumentos de avaliação (GULDENMUND, 2000; OSTROM; WILHELLMSEN; KAPLAN, 1993).

Após o relatório do INSAG sobre o acidente de Chernobyl, Turner e outros (1989 apud PIDGEON, 1991) apresentaram uma primeira definição de cultura de segurança a salientar aspectos verdadeiramente culturais. Para esses autores, a cultura de segurança corresponde a um sistema de significados partilhados por um determinado grupo sobre segurança e que pode ser definido como

\section{[...]o conjunto específico de normas, crenças, funções, atitudes e valores dentro de uma organização, com o objetivo de minimizar a exposição dos empregados, clientes, fornecedores e do público em geral das condições consideradas perigosas ou que causem doenças[...] (TURNER et al., 1989 apud PIDGEON, 1991, p. 7).}

Por sua vez, Cooper (1998) definiu cultura de segurança como o resultado das interações dinâmicas entre três aspectos: 1) os pressupostos básicos e valores; 2) práticas coletivas; e 3) estrutura da organização. Segundo este pesquisador, as interações entre esses aspectos podem variar em intensidade e no tempo. Por exemplo, pode demorar para as mudanças na estrutura da organização influenciar nos valores dos membros da organização.

Para os objetivos deste estudo, optou-se por adotar um conceito de cultura de segurança que fosse coerente com as suas raizes de engenharia, pois esta pesquisa foca nas práticas coletivas e na estrutura existente na organização para dar suporte à segurança. Assim, o conceito de cultura de segurança adotado foi baseado nos conceitos de Reason (1997) e Hopkins (2005), como sendo um conjunto de pressupostos básicos e valores, compartilhados coletivamente pelos membros da organização, que determinam a estrutura e as práticas coletivas com relação à segurança do trabalho.

Esse conceito também possibilita o gerenciamento da cultura a partir das práticas coletivas e da estrutura organizacional, pois elas interagirão com os outros aspectos existentes na cultura organizacional, como os pressupostos básicos e valores, para formar a cultura de segurança (COOPER, 2000; HOPKINS, 2005; REASON, 1997). 
Westrum (1993) criou três estágios de cultura organizacional, baseado nas observações de como o fluxo de informações é tratado na organização: cultura patológica (a informação não flui, é segurada ou usada como vantagem pessoal dentro da organização), cultura calculativa (a informação flui através de canais ou procedimentos formais) e cultura construtiva (a informação flui para a pessoa certa, no momento certo e da forma correta).

Utilizando-se dos estágios de cultura organizacional criados por Westrum (1993), Hudson (2001) propôs um modelo de maturidade para a cultura de segurança. Ele adicionou dois estágios, o reativo e o proativo, aos três existentes, estendendo o modelo para cinco estágios, e trocou o nome do estágio burocrático para calculativo. Nesse modelo, a cultura de segurança evolui de um estágio inicial, o patológico, até um estágio final ideal, o construtivo. A Figura 1 mostra o modelo de maturidade de Hudson (2001).

Abaixo a descrição de cada estágio de maturidade de cultura de segurança do modelo Hudson (2001):

Estágio patológico: Neste estágio não há ações em segurança do trabalho na organização;

Estágio reativo: Neste estágio as ações da organização em segurança do trabalho são realizadas somente depois de acidentes do trabalho terem acontecido;

Estágio calculativo: Neste estágio a organização tem sistema para gerenciar riscos nos locais de trabalho. Ações estão mais voltadas para quantificar os riscos;

Estágio proativo: É o estágio de transição para o estágio da cultura construtivo. O líder, com base nos valores da organização, conduz as melhorias contínuas para a segurança do trabalho. Procura se antecipar aos problemas antes que eles aconteçam;

Estágio construtivo: Existe um sistema integrado de saúde, segurança e meio ambiente, no qual a organização se baseia e se orienta para realizar seus negócios. A organização tem as informações necessárias para gerir o sistema de segurança do trabalho, está

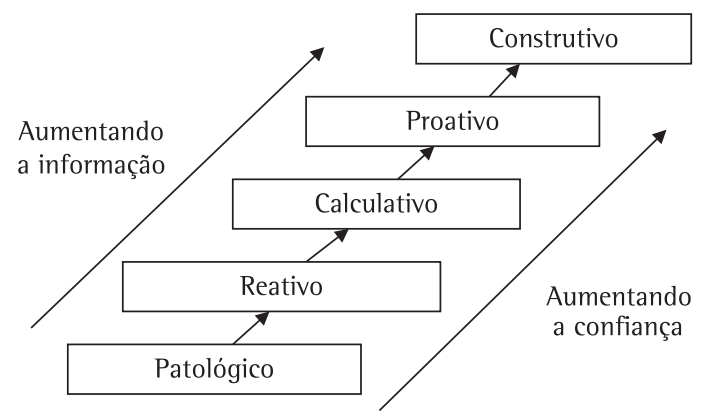

Figura 1. Modelo de maturidade de cultura de segurança. Fonte: Hudson (2001). constantemente tentando melhorar e encontrar as melhores formas de controlar os riscos;

Não existem fatores padrões para serem utilizados como indicativos da maturidade da cultura de segurança, por isso muitos estudos têm sido conduzidos com a finalidade de padronizá-los (FLIN et al., 2000). $\mathrm{Na}$ ausência dessa padronização, as pesquisas com o objetivo de avaliar a cultura de segurança buscam esses fatores na literatura sobre o tema;

Os fatores indicativos da maturidade de cultura de segurança utilizados no modelo desenvolvido nesta pesquisa foram selecionados de uma revisão de literatura de 21 estudos, os cinco fatores mais frequentemente citados nesses estudos foram escolhidos. Essa escolha é corroborada pelos estudos de Flin e colaboradores (2000), Reason (1997), Westrum (1993) e Zohar (1980), que citam os fatores selecionados entre os mais importantes para a caracterizar uma cultura de segurança;

A descrição dos cinco fatores selecionados é apresentada a seguir:

Informação: É a confiança dos indivíduos para relatar os erros, os acidentes e os incidentes ocorridos na organização (REASON, 1997). Incluem também os indicadores que são gerados pela organização para monitorar o desempenho da segurança do trabalho (HUDSON, 2003; AGÊNCIA..., 2002).

Aprendizagem organizacional: É a forma como a organização trata os acidentes, incidentes, as informações recebidas dos empregados e os indicadores de desempenho visando a melhoria da segurança do trabalho (AGÊNCIA..., 2002; REASON, 1997).

Envolvimento: É a participação dos empregados nas questões relacionadas à segurança do trabalho da organização, como, por exemplo, participação na análise dos acidentes e incidentes que lhe diz respeito, na identificação e análise dos riscos existentes no ambiente de trabalho, nas propostas de ações para melhoria da segurança do trabalho e sua implementação, na elaboração e revisão dos procedimentos relacionados com sua atividade e a participação em comitês de segurança, encontros de segurança etc. (GORDON; KIRWAN; PERRIN, 2007).

Comunicação: É a forma, a conveniência e a oportunidade que é feita a comunicação sobre os temas relativos à segurança do trabalho, é a existência de um canal aberto de comunicação entre os empregados e superiores hierárquicos. Inclui também se a comunicação chega aos empregados, se é compreendida por eles e se a organização monitora a efetividade da comunicação (COOPER, 1998; MEARNS; WHITAKER; FLIN, 2003).

Comprometimento: É evidenciado pela proporção de recursos (tempo, dinheiro, pessoas) e suportes 
alocados para a gestão da segurança do trabalho, pelos status da segurança do trabalho em relação à outras atividades da organização, pela existência de um sistema de gestão da segurança do trabalho, onde constam a política de treinamento e qualificação, procedimentos, recompensas, sanções e auditorias (FLIN et al., 2000; AGÊNCIA..., 2002).

\section{Metodologia}

0 modelo desenvolvido nesta pesquisa foi construído tendo como base o modelo proposto por Hudson (2001), que foi o escolhido dentre outros modelos encontrados na literatura por ser o mais completo e não apresentar restrições ao seu uso, possibilitando sua aplicação em maior variedade de empresas. Foram realizadas pequenas alterações nesse modelo com o objetivo de torná-lo mais aderente à realidade onde foi realizada a pesquisa, tais como a troca do nome do estágio calculativo para burocrático, como originalmente proposto por Westrum (1993), e o nome do estágio construtivo para sustentável.

0 modelo descreve como cada um dos cinco fatores (informação, aprendizagem organizacional, envolvimento, comunicação e comprometimento) é tratado em cada um dos cincos estágios de maturidade da cultura de segurança (patológico, reativo, burocrático, proativo e sustentável) (ver Apêndice A - Quadros 3, 4, 5, 6 e 7). Essa descrição foi baseada na literatura (PARKER; LAWRIE; HUDSON, 2006) e na experiência deste pesquisador que trabalha há 11 anos como engenheiro de segurança no cargo de auditor-fiscal do Trabalho do Ministério do Trabalho e Emprego e trabalhou durante 11 anos como engenheiro em plataformas de petróleo e refinaria da Petrobras.

A definição do estágio de maturidade da cultura de segurança utilizando o modelo desenvolvido será feito identificando como a organização trata cada um dos cinco fatores indicativos da maturidade da cultura de segurança e, posteriormente, comparando com o que consta no modelo.

Para testar sua praticidade e validade, o modelo foi aplicado em 23 indústrias químicas e petroquímicas do Polo Industrial de Camaçari, Bahia, Brasil. As razões que levaram a escolha dessas indústrias foram as seguintes: elas completaram 30 anos de operação em 2008, acumulando experiência na área de segurança do trabalho; fazem parte do maior complexo industrial integrado do Hemisfério Sul; o trabalho em petroquímica é perigoso, complexo, contínuo e coletivo; ao lado de riscos catastróficos específicos do processamento de compostos químicos inflamáveis e tóxicos, geradores potenciais de acidentes ampliados e explosões, com consequências para populações vizinhas às fábricas e para o meio ambiente, têm-se os riscos simples e comuns a uma grande variedade de atividades de trabalho industrial menos qualificado, associados à ocorrência de acidentes triviais; a possibilidade de utilizar empresas de mesma atividade econômica e base tecnológica para comparações dos resultados obtidos; e, por fim, a disponibilidade das empresas em participar do projeto.

Um questionário foi elaborado com o objetivo de coletar informações sobre os fatores indicativos da maturidade da cultura de segurança em cada organização estudada e com essas informações identificar o estágio de maturidade da cultura de segurança utilizando o modelo desenvolvido nesta pesquisa. Cada questão do questionário foi elaborada com base nos itens do modelo desenvolvido e os itens foram utilizados como alternativas de respostas das questões.

Para cada questão, o respondente foi solicitado a selecionar o item que melhor representasse o que, no seu entendimento, ocorria na organização onde ele trabalhava. Cada resposta dada representa um estágio de maturidade da cultura de segurança. 0 Quadro 1 mostra, como exemplo, uma das questões com cinco itens para o fator informação.

Antes da aplicação do questionário com o público-alvo da pesquisa, foram realizados pré-testes com os gerentes de segurança do trabalho escolhidos aleatoriamente de cinco empresas petroquímicas que participaram do projeto e com dez empregados também escolhidos aleatoriamente de uma empresa do ramo de mineração. 0 pré-teste seguiu as recomendações de Sinclair (1975), que recomenda uma amostra de até dez participantes para pré-teste de questionário.

0 questionário foi aplicado em duas etapas. $\mathrm{Na}$ primeira etapa foi aplicado com os gerentes de segurança do trabalho de cada uma das 23 empresas químicas e petroquímicas que participaram do

Quadro 1. Uma das questões do questionário com cinco itens para o fator informação.

Questão 1 - Com relação às ocorrências anormais ocorridas na empresa...

1. As ocorrências anormais que acontecem na empresa, independente da gravidade ou se resultaram em acidentes, não são informadas pelos empregados.

2. Somente as ocorrências anormais que resultaram em acidentes graves são informadas pelos empregados.

3. As ocorrências anormais que acontecem na empresa, independente da gravidade ou se resultaram em acidentes, são informadas pelos empregados.

4. A maioria das ocorrências anormais que acontecem na empresa, independente da gravidade ou se resultaram em acidentes, são informadas pelos empregados.

5. A maioria das ocorrências anormais que acontecem na empresa, independente da gravidade ou se resultaram em acidentes, não são informadas pelos empregados. 
projeto. Esses gerentes foram escolhidos por serem os responsáveis pelas questões de segurança do trabalho dessas empresas, sendo, portanto, os mais indicados dentre o corpo gerencial para responder o questionário. 0 questionário foi enviado via correio eletrônico para os gerentes e foi respondido e retornado por todos eles também via correio eletrônico.

Na segunda etapa, o questionário foi aplicado com os empregados de 17 das 23 empresas químicas e petroquímicas participantes do projeto, com o objetivo de conhecer a maturidade da cultura de segurança das empresas pelo lado dos empregados. Não foi aplicado o questionário com os empregados das seis empresas restantes por diferentes motivos: uma empresa alegou que não era o momento de aplicar o questionário com seus empregados devido ao momento que estava passando de corte de gastos; outra foi adquirida por uma das empresas que já havia aplicado o questionário e alegou que não havia necessidade de aplicar em ambas; quatro não retornaram à solicitação de agendamento para aplicar o questionário.

Amostra de empregados para responder o questionário foi do tipo aleatória estratificada não proporcional, com a base de amostragem sendo definida seguindo os seguintes critérios: todas as áreas da empresa (produção, manutenção e administração) deveriam estar representadas, os empregados escolhidos não deveriam exercer cargo de gerência ou supervisão e não deveriam ser de empresas contratadas. Cada empresa apresentava uma lista de empregados que atendiam a esses critérios e eram escolhidos aqueles que responderiam o questionário aleatoriamente pelo pesquisador. Quando por algum motivo o empregado não podia responder o questionário (férias, licença, ausente naquele dia), ele era substituído por outro.

0 tamanho da amostra de empregados que responderiam o questionário foi determinada considerando o total dos empregados das 23 indústrias químicas e petroquímicas que participaram do projeto, que na época da pesquisa era cerca de 4.368 empregados. Para determinação da amostra, utilizou-se a fórmula de cálculo de tamanho de amostra para populações finitas (RICHARDSON et al., 1999 , p. 170), considerando um erro estimado $(E)$ de $7 \%$ e grau de confiança (o) de 90\%, valores usuais para cálculo de amostra. 0 tamanho da amostra calculado foi de 135 empregados, mas 172 responderam o questionário, porque ficou estabelecido que o número mínimo por empresa seria dez empregados, pois com este número seria possível garantir que todas as áreas de cada uma das empresas seriam contempladas.

Os questionários foram aplicados com os empregados selecionados em dia e hora previamente agendados. Os selecionados eram reunidos em uma sala na empresa, o pesquisador thes explicava os objetivos da pesquisa e como eles foram escolhidos. Depois o questionário era distribuído entre os presentes e explicado como respondê-lo, para que as respostas fossem confiáveis. Foi informado também para os participantes que não era necessária a identificação no questionário, para garantir o anonimato dos respondentes. Eles respondiam e devolviam o questionário para o pesquisador no final. 0 tempo médio para responder o questionário foi de 30 minutos.

Para validar o modelo desenvolvido, foram utilizados quatro métodos: 1) entrevistas individuais com os gerentes de segurança que responderam ao questionário; 2) evidências documentais; 3) discussão dos resultados obtidos com grupo de gerentes que responderam ao questionário e 4) aplicação do questionário em outro ramo de atividade que tivesse supostamente estágio de maturidade de cultura de segurança diferente das empresas petroquímicas do Polo Industrial de Camaçari, para avaliar se o modelo media essa diferença.

As entrevistas individuais com os gerentes de segurança do trabalho que responderam o questionário, realizadas após a aplicação do questionário, foram previamente agendadas, feitas no local de trabalho do entrevistado e duraram cerca de uma hora.

A entrevista foi conduzida utilizando um roteiro previamente elaborado de forma que o pesquisador pudesse, usando o modelo desenvolvido, identificar o estágio da cultura de segurança da organização com base nas respostas dos entrevistados.

Depois de cada entrevista individual, o pesquisador solicitava evidências documentais ao entrevistado de como a empresa tratava cada fator do modelo desenvolvido.

As informações obtidas nas entrevistas e nas evidências documentais foram analisadas pelo pesquisador, e com base nessas informações foram identificados os estágios de maturidade de cultura de segurança da organização utilizando o modelo desenvolvido.

A triangulação dos três métodos (questionário, entrevistas individuais e evidências documentais) foi realizada com o objetivo de validar o modelo desenvolvido.

Segundo Hopkins (2006), se os membros das organizações que estão sendo estudadas reconhecem e concordam com a identificação do estágio de maturidade da cultura de segurança, então o pesquisador pode se sentir razoavelmente confiante nos seus achados.

Com o objetivo de validar o modelo desenvolvido por meio do reconhecimento e da concordância dos resultados por parte dos membros das organizações 
estudadas, conforme sugere Hopkins (2006), os estágios de cultura de segurança identificados com a utilização do modelo foram discutidos com um grupo de gerentes de segurança do trabalho dessas organizações.

Para a formação do grupo, duração e forma de registro da reunião foram seguidas as recomendações de Gatti (2005), que são as seguintes: o número preferencial para esse tipo de grupo está entre 6 e 12 pessoas; a duração das reuniões seja entre uma hora e meia e não mais do que três horas; com uma ou duas reuniões deve-se obter as informações necessárias para análise. Nessa pesquisa o grupo foi formado por oito gerentes de segurança do trabalho e realizada uma reunião com duração de 1 hora e 30 minutos.

A reunião foi registrada por meio de gravação em áudio, após prévia autorização dos participantes e garantido o sigilo das informações. Além do registro em áudio, foi utilizado o registro pelo emprego de um relator, que auxiliou o pesquisador nessa tarefa.

Utilizou-se a seguinte dinâmica de grupo: os resultados da pesquisa foram apresentados durante 20 minutos, depois os participantes foram incentivados a discuti-los, apresentarem suas dúvidas, discordâncias e sugestões sobre a pesquisa.

Outra forma de validar o modelo desenvolvido foi aplicá-lo em outro ramo de atividade econômica, onde se supõe que os estágios de maturidade de cultura de segurança fossem diferentes das indústrias químicas e petroquímicas pertencentes ao Polo Industrial de Camaçari. Essa forma de validação segue a recomendação de Shein (2009) de replicar o instrumento para validá-lo.

0 outro ramo de atividade escolhido foi a indústria de fabricação de calçados, pelas seguintes razões: esse ramo de atividade é um dos mais importantes da economia baiana, pois, além de gerar emprego e renda, possui forte presença no interior do estado, contribuindo para a descontração da economia estadual (PITOMBO; ANUNCIAÇÃO, 2010); existem 110 empresas instaladas no estado, que empregam 35 mil trabalhadores (ASSOCIAÇÃO..., 2009); foi o que mais registrou acidentes de trabalho na Bahia no ano de 2008 (BRASIL, 2008); supunha-se que o estágio de maturidade da cultura de segurança da indústria de calçados era diferente das indústrias químicas e petroquímicas do Polo Industrial de Camaçari, pelos seguintes motivos: o maior tempo de operação na Bahia em relação à indústria de calçados e os maiores riscos que envolvem a atividade levaram as indústrias químicas e petroquímicas a desenvolver uma estrutura (comitês, automação de atividades, equipamentos e sistema de gestão) mais avançada voltada para segurança; maior taxa de acidentes na indústria de fabricação calçados nos últimos cinco anos (GONÇALVES FILHO; RAMOS, 2010).

0 método de cálculo do tamanho da amostra quanto à forma de aplicação do questionário com os empregados da indústria de fabricação de calçados foi semelhante à utilizada com os empregados das indústrias químicas e petroquímicas do Polo Industrial de Camaçari.

Para avaliar a confiabilidade do questionário foi utilizado o coeficente Cronbach's alfa, , que é o método estatístico mais comum para medir a confiabilidade de questionário, segundo Field (2009). Valores de variando entre 0.7 e 0.8 indicam boa confiabialidade. Para essa avaliação foram utilizados somente os resultados dos 172 questionários respondidos pelos empregados das indústrias químicas e petroquímicas do Polo Industrial de Camaçari. Para o cálculo do coeficente Cronbach's alfa, , foi utilizado o software aplicativo Statistical Package for the Social Sciences (SPSS), pacote estatístico para as ciências sociais, versão 17.0.2. Os resultados mostrados na Tabela 1 indicam uma boa confiabilidade do questionário utilizado ( $\geq 0.7)$.

Para análise das respostas do grupo de gerentes de segurança do trabalho foi utilizado o método qualitativo do discurso do sujeito coletivo (DSC), conforme apresentado por Lefèvre e Lefèvre (2005).

As seguintes figuras metodológicas são utilizadas para a construção do DSC:

Expressões-chaves (ECH): São pedaços, trechos ou transcrições literais do discurso, que devem ser sublinhados pelo pesquisador, e revelam a essência do depoimento ou, mais precisamente, do conteúdo discursivo dos segmentos em que se desenvolveu a pesquisa.

Ideias centrais (IC): É um nome ou expressão linguística que revela e descreve, da maneira mais sintética, precisa e fidedigna possível, o sentido de cada um dos discursos analisados e de cada conjunto homogêneo de ECH, que vai dar nascimento, posteriormente, ao DSC.

Discurso do sujeito coletivo (DSC): É um discursosíntese do pensamento do grupo redigido na primeira pessoa do singular e composto pelas ECH que têm a mesma IC.

Tabela 1. Valores de alfa de Cronbach.

\begin{tabular}{lc}
\hline \multicolumn{1}{c}{ Fatores } & alfa de Cronbach \\
\hline Informação & 0.634 \\
Aprendizagem organizacional & 0.718 \\
Envolvimento & 0.632 \\
Comunicação & 0.714 \\
Comprometimento & 0.831 \\
\hline
\end{tabular}




\section{Resultados}

0 questionário foi respondido por 23 gerentes de segurança do trabalho e 172 empregados das empresas petroquímicas pesquisadas. 0 Figura 2 mostra os resultados obtidos. As respostas mais frequentes dos dois grupos (gerentes e empregados) são as características dos estágios proativo e sustentável. Embora as diferenças entre os resultados das respostas dos dois grupos não sejam estatisticamente significantes, conforme 0 teste estatístico de Mann-Whitney $(\mathrm{U}=4.000$, não significante, $Z=-1,776$ ), observa-se que as respostas dos empregados apresentam mais características do estágio proativo, enquanto as respostas dos gerentes apresentam mais características do estágio sustentável, o que é compreensível, pois os gerentes tendem a ser menos críticos com relação ao seu trabalho.

Foi utilizado o coeficiente de correlação Kendall's tau, $\tau$, para avaliar a correlação dos dados obtidos por meio do questionário, entrevista individual e evidências documentais. Os dados são fortemente correlacionados quando >0.5 (FIELD, 2009). A Tabela 2 mostra o resultado da correlação entre os dados obtidos pelos três métodos, para cada fator analisado.

A triangulação dos diferentes meios de aplicação do modelo (questionário, entrevista individual e evidências documentais) mostra que os resultados

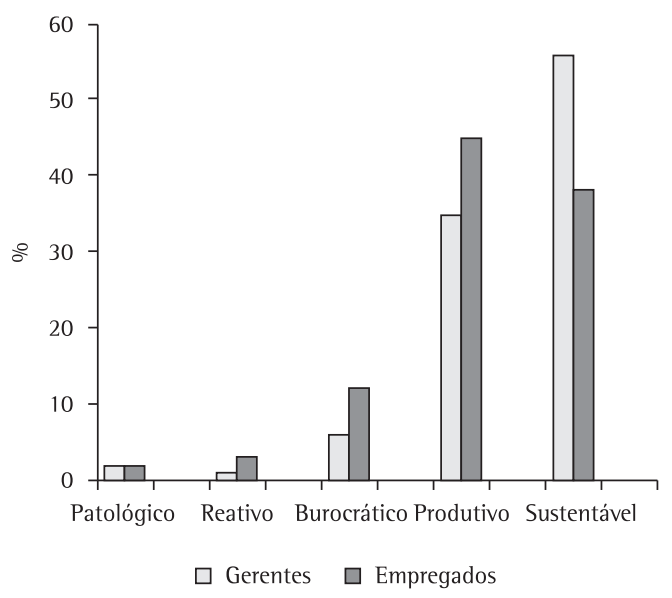

Figura 2. Estágios da cultura de segurança segundo os gerentes e empregados.

Tabela 2. Correlação entre os dados obtidos pelos diferentes métodos.

\begin{tabular}{lc}
\hline \multicolumn{1}{c}{ Fatores } & Tau de Kendall \\
\hline Informação & $0.878^{* * *}$ \\
Aprendizagem organizacional & $0.929^{* *}$ \\
Envolvimento & $0.773^{* *}$ \\
Comunicação & $0.805^{* *}$ \\
Comprometimento & $0.849^{* *}$ \\
\hline
\end{tabular}

${ }^{* *}$ Correlação é significante com $p<0.01$. são fortemente correlacionados, conforme Tabela 2, demonstrando consistência entre os resultados obtidos por esses métodos, reforçando a validade do modelo desenvolvido.

A análise das manifestações dos gerentes na discussão dos resultados obtidos com a aplicação do modelo identificou a seguinte ideia central (IC) para as expressões-chaves (ECH) encontrada nas manifestações (ver Quadro 2) e foi construído o respectivo discurso do sujeito coletivo (DSC) utilizando as ECH:

Ideia central (IC) - Os resultados refletem a realidade das organizações estudadas em relação ao estágio de maturidade da cultura de segurança.

Discurso do sujeito coletivo (DSC) - Os resultados apresentados estão dentro do que eu esperava, do que imagino e enxergo nas organizações. Refletindo as práticas e ações implementadas ao longo dos anos e a maturidade do sistema de segurança existente.

Esse discurso construído a partir das expressões-chaves das manifestações do grupo de gerentes de segurança do trabalho das organizações estudadas demonstra o reconhecimento e a concordância com os resultados por parte deles, reforçando a validade dos dados obtidos pelo modelo desenvolvido.

O Figura 3 mostra a comparação entre os resultados obtidos com a aplicação do questionário com 113 empregados de cinco empresas do ramo de fabricação de calçados instaladas em quatro municípios do estado da Bahia com os resultados obtidos com a aplicação do questionário com os empregados das empresas petroquímicas. Observa-se que as respostas mais frequentes dos empregados do ramo de fabricação de calçados são as características dos estágios burocrático e proativo, estando a maioria das características situada mais ao centro dos cinco estágios de maturidade de cultura de segurança (entre os estágios burocrático e proativo), enquanto que as respostas dos empregados do ramo petroquímico são características situadas no extremo superior dos cinco estágios de maturidade.

Quadro 2. Expressões-chaves das manifestações dos gerentes.

\begin{tabular}{l}
\hline \multicolumn{1}{c}{ Expressões-chaves } \\
\hline Resultado dentro das expectativas \\
Existem empresas melhores do que outras, mas o resultado está \\
dentro do esperado \\
Está de acordo com o que eles falaram \\
0 trabalho reflete o que a gente enxerga e o que é praticado \\
0 resultado reflete a experiência e a maturidade que o sistema já \\
tem \\
Reflete também as ações tomadas em cima dos resultados \\
Reflete o que realmente acontece \\
Está dentro do eu que imaginava \\
Refletem práticas implementadas ao longo dos anos
\end{tabular}




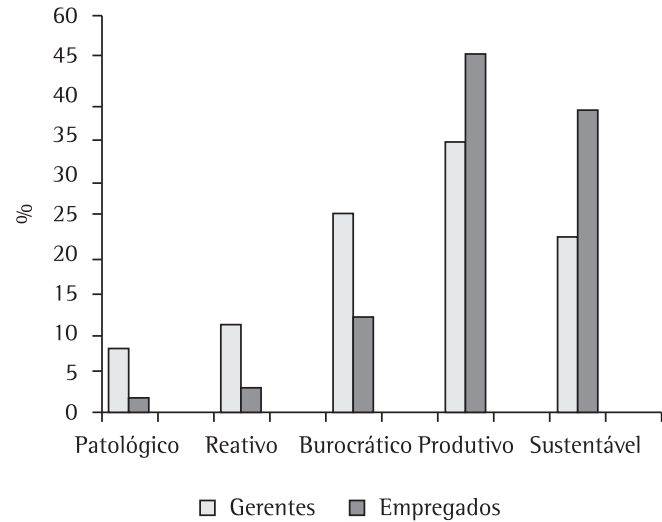

Figura 3. Maturidade de cultura de segurança no setor calçado e petroquímico.

Os resultados das respostas dos empregados da indústria de fabricação de calçados mostram, portanto, que o modelo desenvolvido foi capaz de identificar as diferenças entre a maturidade de cultura de segurança da indústria química e petroquímica do Polo Industrial de Camaçari e das indústrias de fabricação de calçados estudadas nesta pesquisa.

\section{Conclusão}

Considera-se que este trabalho constitui uma contribuição não só para o estudo da segurança do trabalho, mas também para o diagnóstico e intervenção nessa área, com aplicações para a prevenção de acidentes de trabalho, assim como para enfrentar os novos desafios colocados pela globalização e novos contextos de trabalho.

Os resultados obtidos neste trabalho apresentam algumas consequências para os estudos da segurança do trabalho, especificamente pela utilização do modelo desenvolvido que identifica o estágio maturidade da cultura de segurança em organizações industriais.

0 modelo desenvolvido viabiliza os gerentes e pesquisadores a diagnosticar a cultura de segurança de uma grande empresa ou um conjunto de empresas simultaneamente, quando não há recursos e tempo disponíveis para estudá-las de forma mais aprofundada, pois o modelo é de fácil e rápida aplicação, principalmente se utilizado em conjunto com o questionário que foi proposto nesta pesquisa como instrumento de coleta de dados. Com base nesse diagnóstico, eles poderão escolher o setor da empresa ou qual empresa será analisada mais profundamente e definir qual estratégia de intervenção para melhorar sua cultura de segurança.

0 sucesso de uma intervenção na segurança do trabalho em organizações industriais depende da capacidade de realizar um bom diagnóstico da sua situação. 0 modelo permite visualizar algumas características das empresas e revelou uma boa capacidade para discriminar diferenças entre elas, quando mostrou as diferenças entre os estágios de maturidade da cultura de segurança das indústrias químicas e petroquímicas do Polo Industrial de Camaçari e das indústrias de fabricação de calçados.

Assim, recomenda-se que o modelo desenvolvido seja utilizado como uma importante ferramenta de gestão de segurança nas empresas, contribuindo para o sucesso e o bom desempenho do SGST, que, por sua vez, impactará na segurança das operações, dos trabalhadores e na prevenção de acidentes no trabalho.

\section{Referências}

AGÊNCIA INTERNACIONAL DE ENERGIA ATÔMICA - AIEA. Safety séries $n^{\circ} 75$ - INSAG - 4 - Safety Culture. 1991. Disponivel em: <www-pub.iaea.org/MTCD/publication/ PDF/Pub882_web.pdf>. Acesso em: 16 set. 2008.

AGÊNCIA INTERNACIONAL DE ENERGIA ATÔMICA - AIEA. Key practical issues in strengthening safety culture INSAG - 15. 2002. Disponivel em: <www-pub.iaea. org/MTCD/publication/PDF/Pub1137_scr.pdf $>$. Acesso em: 16 set. 2008.

ASSOCIAÇÃO BRASILEIRA DAS INDÚSTRIAS DE CALÇADOS - ABICALÇADOS. Pólos Produtores, 2009. Disponível em: <www.abicalçados.com.br.> Acesso em: 10 jan. 2011.

BRASIL. Ministério da Previdência e Assistência Social. Anuário estatístico de acidentes de trabalho. Brasília, 2007. v.1, p. 1-718. Disponível em: <http://www.mpas.gov. $\mathrm{br} /$ conteudoDinamico.php?id=423>. Acesso em: 15 fev. 2010.

BRASIL. Ministério da Previdência e Assistência Social. Anuário estatístico de acidentes de trabalho. Brasília, 2008. v. 1, p. 1-888. Disponível em: <http://www.mpas.gov. $\mathrm{br} /$ conteudoDinamico.php?id=423>. Acesso em: 15 fev. 2010.

COOPER, D. Improving safety culture: a practical guide. Londres: Wiley, 1998. 318p.

COOPER, M. D. Towards a model of safety culture. Safety Science, n. 36, p. 111-136, 2000.

EK, A. et al. Safety cultura in Swedish air traffic control. Safety Science, n. 45, p. 791-811, 2007. http://dx.doi. org/10.1016/j.ssci.2006.08.017

FIELD, A. Discovering statistics using SPSS. 3. ed. Londres: SAGE, 2009. $821 \mathrm{p}$.

FLIN, R. et al. Measuring climate: identifying the common features. Safety Science, n. 34, p. 177-192, 2000. http:// dx.doi.org/10.1016/S0925-7535(00)00012-6

GATTI, B. A. Grupo focal na pesquisa em ciências sociais e humanas. Brasília: Liber Livro Editora, 2005. 77 p.

GONÇALVES FILHO, A. P.; RAMOS, M. F. Trabalho decente e segurança do trabalhador: análise dos acidentes do trabalho na Bahia no período de 2005 à 2009. Bahia Análise \& Dados, v. 20, n. 2-3, p. 327-337, 2010.

GORDON, R.; KIRWAN, B.; PERRIN, E. Measuring safety culture in a research and development centre: A comparison of two methods in the Air Traffic Management domain. 
Safety Science, n. 45, p. 669-695, 2007. http://dx.doi. org/10.1016/j.ssci.2007.04.004

GULDENMUND, F. W. The nature of safety culture: a review of theory and research. Safety Science, n. 34, p. 193-214, 2000.

HAMALAINEM, P.; TAKALA, J.; SAARELA, K. L. Global estimates of occupational accidents. Safety Science, v. 44, p. 137-156, 2006. http://dx.doi.org/10.1016/j. ssci.2005.08.017

HOPKINS, A. Safety, Culture and Risk: the organizational causes of disasters. Sydney: CCH, 2005. 171 p.

HOPKINS, A. Study organizational cultures and their effects on safety. Safety Science, n. 44, p. 875-889, 2006. http://dx.doi.org/10.1016/j.ssci.2006.05.005

HUDSON, P. Applying the lessons of high risk industries to health care. Quality \& Safety in Health Care, n. 12, p. 17-112, 2003. PMCid:1765769. http://dx.doi. org/10.1136/qhc.12.suppl_1.i7

HUDSON, P. Aviation safety culture. Safeskies, p. 1-23, 2001.

LEFÈVRE, F.; LEFÈVRE, A. M. C. $O$ do sujeito coletivo: Um novo enfoque em pesquisa qualitativa (desdobramentos). Caxias do Sul: Educs, 2005. 256 p.

MEARS, K.; WHITAKER, S. M.; FLIN, R. Safety climate, safety management practice and safety perfornance in offshore environments. Safety Science, n. 41, p. 641-680, 2003. http://dx.doi.org/10.1016/S0925-7535(02)00011-5

NEAL, A.; GRIFFIN, M. A.; HART, P. M. The impacto of organizacional climate on safety climate and individual behavior. Safety Science, n. 34, p. 99-19, 2000. http:// dx.doi.org/10.1016/S0925-7535(00)00008-4
OSTROM, C.; WILHELMSEN, C.; KAPLAN, B. Assessing safety culture. Nuclear Safety, v. 34, n. 2, p. 163-172, 1993.

PARKER, D.; LAWRIE, M.; HUDSON, P. A framework for understand the development of organizational safety culture. Safety Science, n. 44, p. 551-562, 2006. http:// dx.doi.org/10.1016/j.ssci.2005.10.004

PASTORE, J. 0 custo dos acidentes do trabalho. Jornal da Tarde, São Paulo, 21 mar. 2001.

PIDGEON, N. Safety culture and risk management in organizations. Journal of Cross-Cultural Psychology, v. $22, \quad$ n. 1, p. 129-140, 1991. http://dx.doi. org/10.1177/0022022191221009

PITOMBO, J. P.; ANUNCIAÇÃO, C. Indústria de calçados lidera os acidentes de trabalho. A TARDE, Salvador, Economia, Caderno B, p. 4, 25 abr. 2010.

REASON, J. Managing the risks of organizational accidents. Inglaterra: Ashgate Publishing Limited, 1997. 252 p.

RICHARDSON, R. J. et al. Pesquisa social: métodos e técnicas. 3. ed. São Paulo: atlas, 1999. 334 p.

SINCLAIR, M. A. Questionnaire design. Applied Ergonomics, v. 6, n. 2, p. 73-80, 1975. http://dx.doi. org/10.1016/0003-6870(75)90299-9

WESTRUM, R. Cultures with requisite imagination. In: WISE, J. A.; HOPKIN, V. D.; STAGER, P., (Org.). Verification and Validation of Complex Systems: Human Factors lssues. New York: Springer-Verlag, 1993. p. 413-427.

ZOHAR, D. Safety climate in industrial organizations: theorical and applied implications. Journal of Applied Psychology, n. 1, p. 96-102, 1980. PMid:7364709. http://dx.doi. org/10.1037/0021-9010.65.1.96

\title{
Model for safety culture management in industrial organizations
}

\begin{abstract}
The research presented in this article had the objective to develop and validate a model to identify safety culture maturity in industrial organizations. In order to validate it, the developed model was applied in 23 chemical and petrochemical companies in Camaçari, Bahia, Brazil. The following methods were used: 1. individual interviews; 2. interview with groups of safety managers; 3. documental evidence and 4. application of the model in another industrial activity. Results demonstrated that the developed model was validated and it is suitable to identify safety culture maturity in industrial organizations.
\end{abstract}

Keywords

Safety culture maturity. Safety management. Industrial organizations. 


\section{Apêndice A - Modelo desenvolvido.}

Quadro 3. 0 fator informação nos diferentes estágios de maturidade de cultura de segurança.

\begin{tabular}{|c|c|c|c|c|}
\hline \multicolumn{5}{|c|}{ Informação } \\
\hline Patológico & Reativo & Burocrático & Proativo & Sustentável \\
\hline $\begin{array}{l}\text { 1. As ocorrências anormais } \\
\text { que acontecem na empresa, } \\
\text { independente da gravidade ou se } \\
\text { resultaram em acidentes, não são } \\
\text { informadas pelos empregados. }\end{array}$ & $\begin{array}{l}\text { 1. Somente as ocorrências } \\
\text { anormais que resultaram em } \\
\text { acidentes graves são informados } \\
\text { pelos empregados. }\end{array}$ & $\begin{array}{l}\text { 1. A maioria das ocorrências } \\
\text { anormais que acontecem na } \\
\text { empresa, independente da } \\
\text { gravidade ou se resultaram em } \\
\text { acidentes, não são informadas } \\
\text { pelos empregados. }\end{array}$ & $\begin{array}{l}\text { 1. A maioria das ocorrências } \\
\text { anormais que acontecem na } \\
\text { empresa, independente da } \\
\text { gravidade ou se resultaram em } \\
\text { acidentes, são informadas pelos } \\
\text { empregados. }\end{array}$ & $\begin{array}{l}\text { 1. As ocorrências anormais } \\
\text { que acontecem na empresa, } \\
\text { independente da gravidade ou } \\
\text { se resultaram em acidentes, são } \\
\text { informadas pelos empregados. }\end{array}$ \\
\hline $\begin{array}{l}\text { 2. A empresa não oferece meios } \\
\text { que permitem os empregados } \\
\text { informarem qualquer tipo de } \\
\text { ocorrências anormais. }\end{array}$ & $\begin{array}{l}\text { 2. A empresa oferece meios } \\
\text { que permitem os empregados } \\
\text { informarem apenas as ocorrências } \\
\text { anormais que resultaram em } \\
\text { acidentes graves. }\end{array}$ & $\begin{array}{l}\text { 2. A empresa oferece meios } \\
\text { que permitem os empregados } \\
\text { informarem apenas as } \\
\text { ocorrências anormais que } \\
\text { resultaram em acidentes } \\
\text { (independente da gravidade). }\end{array}$ & $\begin{array}{l}\text { 2. A empresa oferece meios } \\
\text { que permitem os empregados } \\
\text { informarem qualquer tipo de } \\
\text { ocorrências anormais. }\end{array}$ & $\begin{array}{l}\text { 2. A empresa oferece meios que } \\
\text { permitem os empregados informar } \\
\text { qualquer tipo de ocorrências } \\
\text { anormais. }\end{array}$ \\
\hline $\begin{array}{l}\text { 3. Os empregados não se sentem } \\
\text { à vontade (não têm confiança) em } \\
\text { informar as ocorrências anormais } \\
\text { que acontecem na empresa. }\end{array}$ & $\begin{array}{l}\text { 3. Os empregados não se sentem } \\
\text { à vontade (não têm confiança) em } \\
\text { informar as ocorrências anormais } \\
\text { que acontecem na empresa. }\end{array}$ & $\begin{array}{l}\text { 3. A minoria dos empregados se } \\
\text { sente à vontade (tem confiança) } \\
\text { em informar as ocorrências } \\
\text { anormais ocorridas na empresa. }\end{array}$ & $\begin{array}{l}\text { 3. A maioria dos empregados se } \\
\text { sente à vontade (tem confiança) } \\
\text { em informar as ocorrências } \\
\text { anormais que acontecem na } \\
\text { empresa. }\end{array}$ & $\begin{array}{l}\text { 3. Todos os empregados se sentem } \\
\text { à vontade (têm confiança) em } \\
\text { informar as ocorrências anormais } \\
\text { ocorridas na empresa. }\end{array}$ \\
\hline $\begin{array}{l}\text { 4. Não existem na empresa índices } \\
\text { de desempenho da segurança no } \\
\text { trabalho. }\end{array}$ & $\begin{array}{l}\text { 4. Os únicos indices de } \\
\text { desempenho da segurança no } \\
\text { trabalho existentes na empresa são } \\
\text { os acidentes graves ocorridos. }\end{array}$ & $\begin{array}{l}\text { 4. Os únicos índices de } \\
\text { desempenho da segurança no } \\
\text { trabalho existentes na empresa } \\
\text { são as taxas de acidentes } \\
\text { ocorridos. }\end{array}$ & $\begin{array}{l}\text { 4. A empresa possui outros } \\
\text { indices de desempenho da } \\
\text { segurança no trabalho, além das } \\
\text { taxas de acidentes ocorridos. }\end{array}$ & $\begin{array}{l}\text { 4. A empresa possui outros índices } \\
\text { de desempenho da segurança } \\
\text { no trabalho, além das taxas de } \\
\text { acidentes ocorridos. }\end{array}$ \\
\hline
\end{tabular}

Quadro 4. 0 fator aprendizagem organizacional nos diferentes estágios de maturidade de cultura de segurança.

\begin{tabular}{|c|c|c|c|c|}
\hline \multicolumn{5}{|c|}{ Aprendizagem organizacional } \\
\hline Patológico & Reativo & Burocrático & Proativo & Sustentável \\
\hline $\begin{array}{l}\text { 1. A empresa não faz análise das } \\
\text { ocorrências anormais. } \\
\text { 2. A análise das ocorrências } \\
\text { anormais feita pela empresa se } \\
\text { restringe a identificar os culpados } \\
\text { pelas ocorrências. } \\
\text { 3. A empresa não faz melhorias em } \\
\text { segurança no trabalho. } \\
\text { 4. A empresa não informa } \\
\text { o resultado das análises das } \\
\text { ocorrências anormais para os } \\
\text { empregados. }\end{array}$ & $\begin{array}{l}\text { 1. A empresa faz análise apenas } \\
\text { das ocorrências anormais que } \\
\text { resultaram em acidentes graves. } \\
\text { 2. A análise das ocorrências } \\
\text { anormais feita pela empresa se } \\
\text { restringe a identificar as causas } \\
\text { imediatas das ocorrências. } \\
\text { 3. A empresa faz melhorias em } \\
\text { segurança no trabalho apenas } \\
\text { quando ocorrem acidentes graves. } \\
\text { 4. A empresa informa o resultado } \\
\text { da análise das ocorrências anormais } \\
\text { apenas aos empregados envolvidos } \\
\text { com a ocorrência. }\end{array}$ & $\begin{array}{l}\text { 1. A empresa faz análise apenas } \\
\text { das ocorrências anormais } \\
\text { que resultaram em acidentes } \\
\text { (independente da gravidade). } \\
\text { 2. A análise das ocorrências } \\
\text { anormais feita pela empresa se } \\
\text { restringe a identificar falhas das } \\
\text { máquinas, dos equipamentos, da } \\
\text { manutenção e dos empregados. } \\
\text { 3. A empresa faz melhorias em } \\
\text { segurança no trabalho apenas } \\
\text { nos setores onde há riscos de } \\
\text { acidentes. } \\
\text { 4. A empresa informa o resultado } \\
\text { da análise das ocorrências } \\
\text { anormais apenas aos empregados } \\
\text { do setor envolvido com a } \\
\text { ocorrência. }\end{array}$ & $\begin{array}{l}\text { 1. A empresa faz análise da } \\
\text { maior parte das ocorrências } \\
\text { anormais. } \\
\text { 2. A análise das ocorrências } \\
\text { anormais feita pela empresa } \\
\text { abrange a empresa como um } \\
\text { todo, tais como os processos de } \\
\text { trabalho, decisões gerenciais que } \\
\text { influenciaram na ocorrência, os } \\
\text { procedimentos de trabalho, a } \\
\text { contribuição das máquinas e das } \\
\text { pessoas para a ocorrência. } \\
\text { 3. A empresa faz continuamente } \\
\text { melhorias em segurança do } \\
\text { trabalho. } \\
\text { 4. A empresa informa apenas } \\
\text { o resultado das análises dos } \\
\text { acidentes graves para todos os } \\
\text { empregados. }\end{array}$ & $\begin{array}{l}\text { 1. A empresa faz análise de todas as } \\
\text { ocorrências anormais, independente } \\
\text { da gravidade ou se resultaram em } \\
\text { acidentes. } \\
\text { 2. A análise das ocorrências } \\
\text { anormais feita pela empresa } \\
\text { abrange a empresa como um } \\
\text { todo, tais como os processos de } \\
\text { trabalho, decisões gerenciais que } \\
\text { influenciaram na ocorrência, os } \\
\text { procedimentos de trabalho, a } \\
\text { contribuição das máquinas e das } \\
\text { pessoas para a ocorrência. } \\
\text { 3. A empresa faz continuamente } \\
\text { melhorias em segurança do } \\
\text { trabalho. } \\
\text { 4. A empresa informa os resultados } \\
\text { das análises das ocorrências } \\
\text { anormais para todos os empregados } \\
\text { para compartilhar as lições } \\
\text { aprendidas. }\end{array}$ \\
\hline
\end{tabular}

Quadro 5. 0 fator comunicação nos diferentes estágios de maturidade de cultura de segurança.

\begin{tabular}{|c|c|c|c|c|}
\hline \multicolumn{5}{|c|}{ Comunicação } \\
\hline Patológico & Reativo & Burocrático & Proativo & Sustentável \\
\hline $\begin{array}{l}\text { 1. As notícias sobre segurança no } \\
\text { trabalho não são divulgadas pela } \\
\text { empresa. } \\
\text { 2. Não existe um canal aberto de } \\
\text { comunicação entre a empresa e } \\
\text { os empregados para falar sobre } \\
\text { segurança no trabalho. } \\
\text { 3. A comunicação sobre segurança } \\
\text { no trabalho feita pela empresa } \\
\text { não chega aos empregados. }\end{array}$ & $\begin{array}{l}\text { 1. As notícias sobre segurança no } \\
\text { trabalho somente são divulgadas } \\
\text { pela empresa quando ocorrem } \\
\text { acidentes graves. } \\
\text { 2. Existe um canal aberto de } \\
\text { comunicação entre a empresa e } \\
\text { os empregados para falar sobre } \\
\text { segurança no trabalho apenas } \\
\text { quando acontecem acidentes } \\
\text { graves. } \\
\text { 3. A comunicação sobre segurança } \\
\text { no trabalho feita pela empresa } \\
\text { não chega aos empregados. }\end{array}$ & $\begin{array}{l}\text { 1. As notícias sobre segurança no } \\
\text { trabalho divulgadas pela empresa } \\
\text { limitam-se as previstas em normas } \\
\text { de segurança, como, por exemplo, } \\
\text { sobre uso do equipamento de } \\
\text { proteção individual (EPI) e a } \\
\text { Comissão Interna de Prevenção de } \\
\text { Acidentes (CIPA). } \\
2.0 \text { canal de comunicação entre } \\
\text { a empresa e os empregados para } \\
\text { falar segurança no trabalho é } \\
\text { formal (com base em normas } \\
\text { e procedimentos da empresa, } \\
\text { como, por exemplo, na Comissão } \\
\text { Interna de Prevenção de Acidentes } \\
\text { (CIPA) e em reuniões formais de } \\
\text { trabalho). } \\
\text { 3. A comunicação sobre segurança } \\
\text { no trabalho feita pela empresa } \\
\text { chega à minoria dos empregados. }\end{array}$ & $\begin{array}{l}\text { 1. As notícias sobre segurança no } \\
\text { trabalho divulgadas pela empresa } \\
\text { são diversas, tais como o uso } \\
\text { do equipamento de proteção } \\
\text { individual (EPI), palestras sobre } \\
\text { segurança, indices de acidentes, } \\
\text { resultados de análises de } \\
\text { ocorrências anormais, proteção } \\
\text { à saúde, melhorias realizadas } \\
\text { em segurança no trabalho, entre } \\
\text { outros. } \\
\text { 2. Existe um canal aberto de } \\
\text { comunicação entre a empresa e } \\
\text { os empregados para falar sobre } \\
\text { segurança no trabalho. } \\
\text { 3. A comunicação sobre } \\
\text { segurança no trabalho feita pela } \\
\text { empresa chega à maioria dos } \\
\text { empregados. }\end{array}$ & $\begin{array}{l}\text { 1. As notícias sobre segurança no } \\
\text { trabalho divulgadas pela empresa } \\
\text { são diversas, tais como o uso } \\
\text { do equipamento de proteção } \\
\text { individual (EPI), palestras sobre } \\
\text { segurança, índices de acidentes, } \\
\text { resultados de análises de } \\
\text { ocorrências anormais, proteção } \\
\text { à saúde, melhorias realizadas } \\
\text { em segurança no trabalho, entre } \\
\text { outros. } \\
\text { 2. Existe um canal aberto de } \\
\text { comunicação entre a empresa e } \\
\text { os empregados para falar sobre } \\
\text { segurança no trabalho. } \\
\text { 3. A comunicação sobre segurança } \\
\text { no trabalho feita pela empresa } \\
\text { chega a todos os empregados. }\end{array}$ \\
\hline
\end{tabular}


Quadro 6. 0 fator comprometimento nos diferentes estágios de maturidade de cultura de segurança.

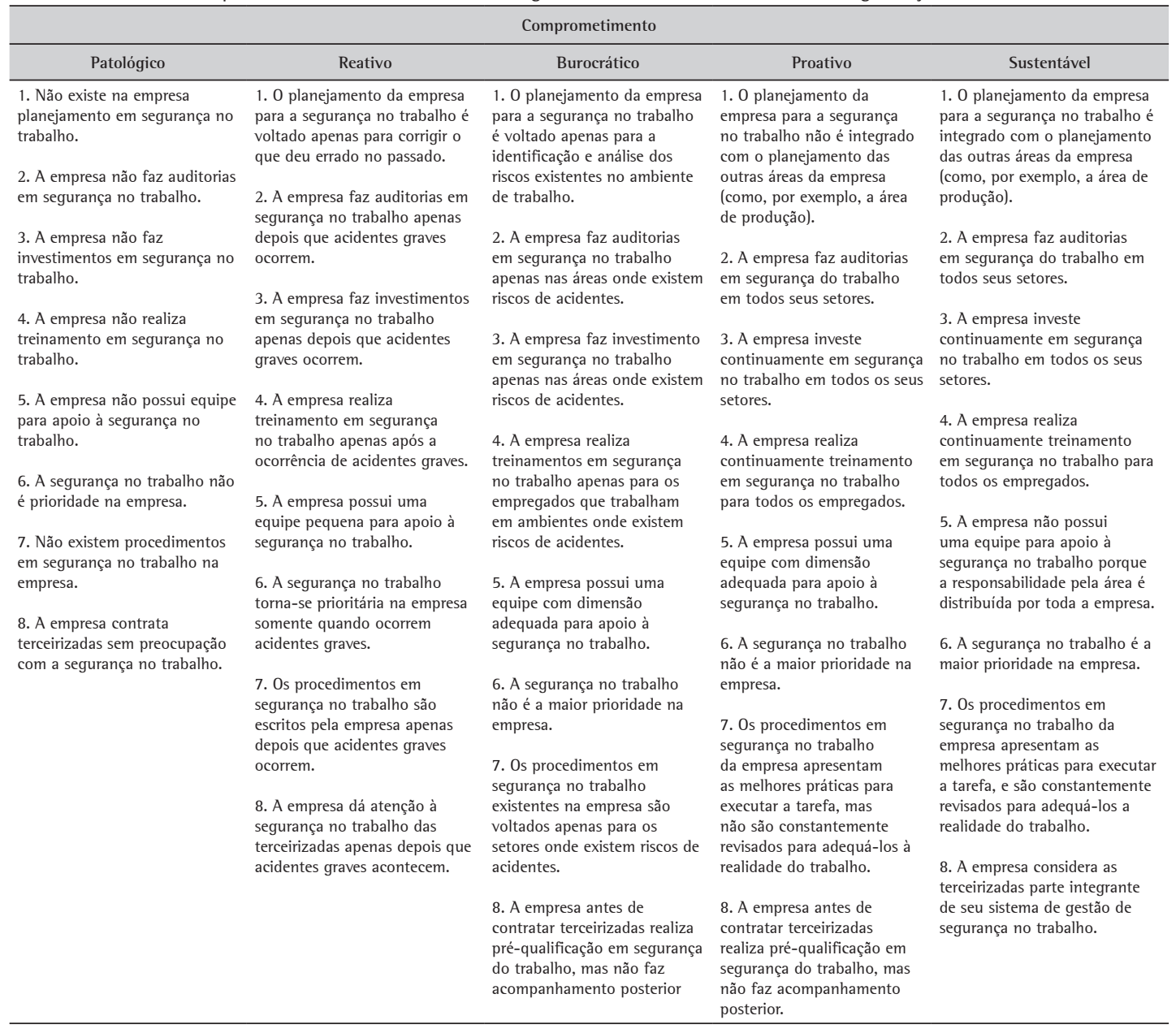

Quadro 7. 0 fator envolvimento nos diferentes estágios de maturidade de cultura de segurança.

\begin{tabular}{|c|c|c|c|c|}
\hline \multicolumn{5}{|c|}{ Envolvimento } \\
\hline Patológico & Reativo & Burocrático & Proativo & Sustentável \\
\hline $\begin{array}{l}\text { 1. Os empregados não } \\
\text { participam das questões sobre } \\
\text { segurança no trabalho da } \\
\text { empresa. }\end{array}$ & $\begin{array}{l}\text { 1. Os empregados participam } \\
\text { das questões sobre segurança } \\
\text { no trabalho apenas quando } \\
\text { ocorrem acidentes graves na } \\
\text { empresa. }\end{array}$ & $\begin{array}{l}\text { 1. A minoria dos empregados } \\
\text { participa das questões sobre } \\
\text { segurança no trabalho da } \\
\text { empresa. }\end{array}$ & $\begin{array}{l}\text { 1. A maioria dos empregados } \\
\text { participa das questões sobre } \\
\text { segurança no trabalho da } \\
\text { empresa. }\end{array}$ & $\begin{array}{l}\text { 1. Todos os empregados } \\
\text { participam das questões sobre } \\
\text { segurança no trabalho da } \\
\text { empresa. }\end{array}$ \\
\hline $\begin{array}{l}\text { 2. Os empregados não se } \\
\text { interessam em participar das } \\
\text { questões sobre segurança no } \\
\text { trabalho na empresa. }\end{array}$ & $\begin{array}{l}\text { 2. Os empregados se } \\
\text { interessam em participar das } \\
\text { questões sobre segurança } \\
\text { no trabalho apenas quando } \\
\text { ocorrem acidentes graves na } \\
\text { empresa. }\end{array}$ & $\begin{array}{l}\text { 2. A minoria dos empregados } \\
\text { se interessa em participar das } \\
\text { questões sobre segurança no } \\
\text { trabalho na empresa. }\end{array}$ & $\begin{array}{l}\text { 2. A maioria dos empregados } \\
\text { se interessa em participar das } \\
\text { questões sobre segurança no } \\
\text { trabalho na empresa. }\end{array}$ & $\begin{array}{l}\text { 2. Todos os empregados se } \\
\text { interessam em participar das } \\
\text { questões sobre segurança no } \\
\text { trabalho na empresa. }\end{array}$ \\
\hline
\end{tabular}

